\title{
Clinicopathological Analysis of Patients with Malign Melanoma
}

\section{Malign Melanomlu hastaların klinikopatolojik incelenmesi}

\author{
Hüsrev Önder Aydın ${ }^{1}$, Olçun Ümit Ünal ${ }^{2}$, Işıl Somalı ${ }^{3}$, İhan Öztop ${ }^{3}$, Ahmet Uğur Yılmaz ${ }^{4}$
}

\author{
${ }^{1}$ Dokuz Eylül Üniversitesi Tıp Fakültesi İç Hastalıkları Ana Bilim Dalı,izmir, Türkiye. \\ ${ }^{2}$ İzmir Bozyaka Eğitim Ve Araştırma Hastanesi Tıbbi Onkoloji Bölümü, İzmir, Türkiye. \\ ${ }^{3}$ Dokuz Eylül Üniversitesi Tıp Fakültesi İç Hastalıkları Ana Bilim Dalı,tıbbi Onkoloji Bilim Dalı, İzmir, \\ Türkiye. \\ ${ }^{4}$ İzmir Üniversitesi Tıp Fakültesi İç Hastalıkları Ana Bilim Dalı,tıbbi Onkoloji Bilim Dalı, İzmir, Türkiye.
}

Dergiye Ulaşma Tarihi:14/07/2015 Dergiye Kabul Tarihi:15/08/2015 Doi: 10.5505/aot.2015.57060

\section{ÖZET}

GíRiş ve AMAÇ: Bu çalışmada Malign Melanom tanılı hastaların Klinikopatolojik özelliklerini incelemeyi amaçladik.

YÖNTEM ve GEREÇLER: Bu çalışmada Dokuz Eylül Üniversitesi Hastanesi Tıbbi Onkoloji bölümünde 1991-2011 Yilları arasında takip edilen malign melanom tanılı 166 hasta retrospektif olarak değerlendirilmiştir. BULGULAR: Hastalardan 87'si erkek, 79'u kadındır. Tüm hastaların ortanca yaşı 52 (21-81) dir. En sık extremite bölgesinde malign melanom görülürken daha az sıklıkta baş boyun ve gövdede gözlenmiştir. Primer tümör bölgesi ile breslow kalınlığı arasında istatistiksel bir anlamlılık saptanmamıştır $(\mathrm{p}=0.109)$. Ancak breslow kalınlığı ile sağ kalım arasında istatistiksel bir fark bulunmuştur. Breslow kalınlığı 0-2 mm arasında olanların ortalama sağkalımı 125,6 ay(99-151), 2-4 mm arasında olanların ortalama sağkalımı 121,2 ay(92-151), 4 mm ve üstünde olanların ortalama sağkalımı 89 ay(68-111) olarak saptanmıştır ve aradaki fark istatistiksel olarak anlamlı saptanmıştır( $\mathrm{p}=0,012)$. Tüm hastaların 1 yıllık sağkalım oranı $\% 96$, iki yıllık sağkalım oranı $\% 92.1$ ve 5 yıllık sağkalım oranı \%82.7 saptanırken; ortalama sağkalım süresi $89,74 \pm 6,9$ ay olarak saptanmıştır. Kadın cinsiyette ortalama sağkalım 108.8 ay, erkeklerde ortalama sağkalım 72.7 ay saptanmış olup aradaki fark istatistiksel olarak anlamlı bulunmuştur $(\mathrm{P}=0,001)$. Melanomun primer yerleşim yerine göre sağkalımları sırasıyla baş-boyun yerleşiminde 69.6 ay, gövde 114.1 ay, extremite yerleşiminde 82.0 ay olup aradaki fark istatistiksel olarak anlamlı saptanmamıştır $(\mathrm{P}=0,32)$.

TARTIŞMA ve SONUÇ: Malign melanom en kötü seyirli deri tümörü olup prognozu etkileyen faktörler birden fazladır. Bu çalışmada en önemli prognostik faktörler breslow kalınlığı, primer tümör yerleşim bölgesi ve cinsiyet olarak saptanmıştır.

Anahtar Kelimeler: Malign melanoma, prognoz.

\section{ABSTRACT}

INTRODUCTION: Our aim in this study is to analyse patients with malign melanoma clinicopathologically. METHODS: In this study, 166 malign melanoma patients that followed by Dokuz Eylul University Hospital Medical Oncology Clinic in years between 1996 and 2011 were evaluated retrospectively. RESULTS: 87 of patients is male, 79 is female. The median age is 52 (21-81). The most common site for malign melanoma is extremity; head, neck and body are less commonly involved. There is no statistically significant difference between primary tumor site and breslow thickness $(\mathrm{p}=0.109)$. Breslow thickness and survival are related statistically significant. Average survival time for Breslow thickness between 0 and $2 \mathrm{~mm}$ is 125,6 months (99-151), 2 and $4 \mathrm{~mm}$ is 121,2 months (92-151) and over $4 \mathrm{~mm}$ is 89 months (68-111) and difference between groups are statistically significant $(\mathrm{p}=0,012)$. 1 year survival rate for all patients is $96 \%, 2$ year survival rate is $92.1 \%$ and 5 year survival rate is $82.7 \%$. Average survival time is detected as $89,74 \pm 6,9$ months. Mean survival time for female patients is 108.8 months, 72.9 months for male patients which is statistically significant $(\mathrm{P}=0,001)$. There is no significant difference in survival due to melanom primary site $(\mathrm{P}=0,32)$. The mean survival time for head-neck malign melanoma is 69.6 months, 114.1 months for body involvement and 82.0 months for extremity involvement.

DISCUSSION AND CONCLUSION: Malign melanoma has the worst progress in all skin cancers and there are several factors affecting the prognosis. The most important prognostic factors detected in this study are breslow thickness, primary tumor site and sex.

Key words: Malignant melanoma, prognosis. 


\section{GíRiș}

Melanom nöral krest kaynaklı pigment üreten melanositlerden köken alan malign neoplazidir. Melanositler beyin ve medulla spinaliste matriks oluşturan nöro-ektodermal krest hücrelerinden köken alırlar ve erken fetal dönemde daha sonra bulunacakları bölgelere göç ederler(1,2). Melanositlerin en önemli görevi ultraviole 1şınlarını 1sı enerjisine dönüştürerek yayan ve cildi bu zararlı 1şınlardan koruyan melanin pigmenti üretmektir.

Kuzey ülkeleri başta olmak üzere dünyada melanomun siklığ 1 artmaktadır. En önemli risk faktörü güneş 1şığı(ultraviole) olmasına rağmen, etyopatogenezde başka faktörlerde rol oynar(3). Melanom cilt kanserlerinin \% 5'inden daha az bölümünü oluştursa da, uzak metastaz yapma ve kanserden ölüme neden olma sıklığının artması nedeniyle son yıllarda üzerinde oldukça fazla durulan bir kanser türüdür. $\mathrm{Bu}$ arada cilt dış1 yerleşimlerde de görülen bir kanser olsa da bu oran tüm melanomların \% 5'ini geçmez. Sıklıkla çıplak gözle ayırt edilebilen bir kanserdir, bu özellik izlem açısından önemlidir. Ayrıca bu durum daha kolay ulaşılabilir bir kanser olmasına yol açar.

Epidemiyolojik araştırmalar ve hastalığın doğal seyri dikkate alınırsa melanom dış1 cilt kanserlerinde ve prekanseröz lezyonlarda güneş 1şının kümülatif etkisi ön planda iken melanomda güneş 1şınlarına aralıklı ve şiddetli maruziyet ön plandadır. Tümör, yüz, eller, kollar gibi güneşe sürekli değil; gövde, bacak arkası gibi aralıklı maruz kalan bölgelerde daha sık görülmektedir.

Malign Melanom çevre şartlarından etkilenen bir hastalıktır. Güneş 1şığına maruziyet bir risk faktörüdür.Fakültemiz bulunduğu konum itibariyle daha çok Ege bölgesi hastalarına hitap etmektedir.Ege bölgesi ülkemizde görece güneş ışığının fazla olduğu bir bölgedir.Dolayısıyla İzmir ve çevresindeki Malign Melanom hastaların klinikopatolojik olarak değerlendirme imkanımız olacaktır.Ayrıca Türkiye'de malign melanom hastalarının özelliklerinin belirlenmesine yönelik çalışmaların sayısı oldukça azdır.Bu çalışmanın Türkiye veri tabanına bir katkıda bulunmasını amaçladık.

\section{GEREÇ VE YÖNTEM}

Çalışma planlanırken öncelikle taranacak parametreler belirlendi. Plan sonrası Dokuz Eylül Üniversitesi Girişimsel Olmayan Araştırmalar Etik Kurulundan 08.03.2012 tarih ve 522-GOA protokol numarasi ve 2012/09-24 karar numarası ile çalışma için izin alınmıştır.

\section{Hasta seçimi:}

$\mathrm{Bu}$ çalışmada Dokuz Eylül Üniversitesi Hastanesi Tibbi Onkoloji bölümünde ocak 1996-aralık 2011 Y1lları arasında takip edilen malign melanom tanıl1 166 hasta retrospektif olarak değerlendirilmiştir. Öncelikle hastane otomasyon sistemine malign melanom ICD kodu girilerek 334 tane malign melanomlu hastanın bilgisine ulaşılmıştır.Daha sonra bu hastalar Tibbi Onkolojinin kendi arşivinden taranarak 240 hasta dosyası bulunmuştur. 84 hasta dişlama kriterleri içinde olduğu için çalışmaya dahil edilmemiştir. Çalışmaya dahil edilen tüm hastaların demografik ve klinik verileri olan tanıda yaş, cinsiyet, metastaz, tümörün yeri, breslow kalınlığ 1 , son kontrol tarihi, ilk metastaz tarihi, exitus tarihi Tibbi Onkoloji dosyalarındaki veriler ve hastane otomasyon sistemi baz alınarak kaydedildi. Tümörün ortalama görülme yaşına bakıldı. Ayrıca cinsiyete, yaşa, breslow kalınlığına, genel sağ kalıma ve lokalizasyona göre ortalama sağ kalıma bakıldı. Yine lokalizasyona göre breslow kalınlığında anlamlı bir fark olup olmadığına bakılarak analiz edildi. Çalışmaya alınma ve dışlama kriterleri aşağıdaki gibidir:

Çalışmaya alınma kriterleri;

1) Malign melanom tanısı almış olmak

2) Evrelendirme tetkiklerinin yapılmış olmas1

3) Hasta dosyalarında klinik ve patolojik özelliklerinin olması

4)Takip ve tedavilerini hastanemizde sürdürmek

Dışlama kriterleri; olmak

1)Hasta dosyalarındaki bilgileri eksik

2)Dış merkezde tanı almış ama parafin blokları hastanemiz patoloji bölümünde doğrulanmamış olmak

3)Tedavi ve takiplerine gelmemiş, telefonla kendilerine ulaşılamamış olmak

Değerlendirilen Parametreler ve Yöntem: Çalışmaya dahil edilen tüm hastaların 
demografik ve klinik verileri olan tanıda yaş, cinsiyet, metastaz, tümörün yeri, breslow kalınlığı, son kontrol tarihi, ilk metastaz tarihi, exitus tarihi onkoloji dosyalarındaki veriler ve hastane otomasyon sistemi baz alınarak kaydedildi. Hastanın histopatolojik tanısı onkoloji dosyasındaki veya hastane otomasyon sistemindeki patoloji raporlarından elde edildi. Tümörün lokalizasyonu ve metastaz yeri Pozitron Emisyon Tomografisi, Bilgisayarlı Tomografi, manyetik rezonans görüntüleme, kemik sintigrafisi, direkt grafiler gibi görüntüleme yöntemleri kullanılarak tespit edildi. Son dönem genel ve hastalıksız sağ kalım oranlarını değerlendirmek amacıyla hastaların ilk tanı tarihleri, hastaneye son başvuru tarihleri ve yaşamını yitiren hastaların ölüm tarihleri hastane otomasyon sistemi ve onkoloji hasta dosyaları yardımıyla elde edildi. Hastane otomasyon sistemi ve onkoloji hasta dosyalarındaki bilgiler doğru olarak kabul edildi. Altı ay ve daha uzun süreyle kontrol amaçlı hastaneye başvurmayan hastaların son durumlarının belirlenmesi için telefon aracılığıyla hasta veya yakınlarına ulaşıldı.

İstatiksel Analiz: Tüm veriler SPSS (Statistical Package for Social Sciences) 15.0 istatistik programına kaydedildi.

\section{SONUCLAR}

Bu çalışmada Dokuz Eylül Üniversitesi Hastanesi Trbbi Onkoloji bölümünde 19962011yılları arasında takip edilen malign melanom tan1l 166 hasta retrospektif olarak değerlendirilmiștir. Erkek/kadın oranı 1.1/1 dir. Tüm hastaların ortanca yaşı 52 (21-81) dır. En s1k extremite bölgesinde malign melanom görülürken daha az sıklıkta baş boyun ve gövdede gözlenmiştir. Hastalardan 76'sında tanı anında veya sonradan metastaz saptandi. En sik metastaz akciğerlere sonra sirasıyla karaciğer, beyin ve kemiğe saptanmıştır. Hasta özellikleri tablo 1'de ayrıntılı olarak gösterilmiștir.

Hastaların primer tümör yerleşim bölgesi ile breslow kalınlığı arasındaki ilişki tablo 2'te gösterilmiștir. Primer tümör bölgesi ile breslow kalınlığ 1 arasında istatistiksel bir anlamlılık saptanmamıştır( $\mathrm{p}=0.109)$.

Tüm hastaların 1 yıllık sağkalım oranı \% 96, iki yıllık sağkalım oranı \% 92.1 ve 5 yıllık sağkalım oranı \% 82.7 saptanırken; ortalama sağkalım süresi $89,74 \pm 6,9$ ay olarak saptanmıştır. Tüm hastaların ortalama sağkalım eğrisi şekil 1 'de gösterilmektedir.

Kadın cinsiyette ortalama sağkalım 108.8 ay, erkeklerde ortalama sağkalım 72.7 ay saptanmış olup aradaki fark istatistiksel olarak anlamlı bulunmuştur $(\mathrm{P}=0,001)$. Cinsiyete özel sağkalım eğrisi şekil 2 de gösterilmektedir.

Melanomun primer yerleşim yerine göre sağkalımları sırasıyla baş-boyun yerleşiminde 69.6 ay, gövde 114,1 ay, ekstremite yerleşiminde 82.0 ay olup aradaki fark istatistiksel olarak anlaml saptanmamıştır $(\mathrm{P}=0,32)$. Yerleşim yerine göre sağkalım eğrisi şekil 3 de verilmiştir.

Breslow kalınlığ $0-2 \quad \mathrm{~mm}$ arasında olanların ortalama sağkalımı 125,6 ay(99-151), 2-4 mm arasında olanların ortalama sağkalımı 121,2 ay(92-151), $4 \mathrm{~mm}$ ve üstünde olanların ortalama sağkalımı 89 ay(68-111) olarak saptanmıştır ve aradaki fark istatistiksel olarak anlamlı saptanmıştır( $(\mathrm{p}=0,012)$. Breslow kalınlığına göre hastaların sağkalım eğrisi şekil 4'te gösterilmektedir.

Tablo 1. Hasta özellikleri

\begin{tabular}{|l|l|}
\hline Cinsiyet & $87(\% 52.4)$ \\
Erkek & $79(\% 47.6)$ \\
Kadın & $52(21-81)$ \\
\hline Yaş(ortanca,aralık) & \\
\hline Yer & $68(\% 41)$ \\
Extremite & $52(\% 31.3)$ \\
Başboyun & $46(\% 27.7)$ \\
Gövde & \\
\hline Breslow kalınlığı & $19(\% 11.4)$ \\
$0-1 \mathrm{~mm}$ & $11(\% 6.6)$ \\
$1-2 \mathrm{~mm}$ & $20(\% 12)$ \\
$2-4 \mathrm{~mm}$ & $79(\% 47.7)$ \\
4 mm ve üstü & $37(\% 22.3)$ \\
Bilinmeyen & \\
\hline Lenf Bezi metastazı & $73(\% 44)$ \\
Var & $86(\% 51.8)$ \\
Yok & $7(\% 4.2)$ \\
Bilinmiyor & \\
\hline Metastaz bölgeleri & $36(\% 21.7)$ \\
Akciğer & $27(\% 16.3)$ \\
Karaciğer & $17(\% 10.2)$ \\
Beyin & $10(\% 6)$ \\
Kemik & $44(\% 26.5)$ \\
Diğer &
\end{tabular}

* Diğer metastazlar: Göz, böbrek, rektum, lenf bezi. 
Tablo 2. Primer tümör yerleşim bölgesi ile breslow kalınlığı arasındaki ilişki

\begin{tabular}{|l|l|l|l|}
\hline $\begin{array}{l}\text { Primer } \\
\text { tümör } \\
\text { bölgesi }\end{array}$ & $0-2 \mathrm{~mm}$ & $2-4 \mathrm{~mm}$ & $\begin{array}{l}4 \quad \mathrm{~mm} \\
\text { ve üstü }\end{array}$ \\
\hline $\begin{array}{l}\text { Baş- } \\
\text { boyun }\end{array}$ & $\begin{array}{l}4 \\
(\% ~ 11,8)\end{array}$ & $\begin{array}{l}7 \\
(\% ~ 20,6)\end{array}$ & $\begin{array}{l}23 \\
(\% \\
67.6)\end{array}$ \\
\hline Gövde & $\begin{array}{l}5 \\
(\% ~ 14.3)\end{array}$ & $\begin{array}{l}12 \\
(\% ~ 34.3)\end{array}$ & $\begin{array}{l}18 \\
(\% \\
51.4)\end{array}$ \\
\hline extremite & $\begin{array}{l}10 \\
(\% ~ 20.4)\end{array}$ & $\begin{array}{l}15 \\
(\% ~ 30.6)\end{array}$ & $\begin{array}{l}24 \\
(\% ~ 49)\end{array}$ \\
\hline
\end{tabular}

\section{TARTIŞMA}

Melanom bilinen mortalitesi en yüksek deri tümörü olup, son yıllarda insidansinda artış görülmektedir. Bu daha çok son yıllarda yaşam süresinde uzama ve bu nedenle güneşe maruziyetin artışına bağlanmaktadır. Malign melanomda literatür tarandığında belirli prognostik faktörler tanımlanmıştır; örneğin yaş, hastalığın evresi, breslow kalınlığı, belirli lokalizasyonlarda olması gibi. Bu retrospektif çalışmada hastalarımızın klinik özellikleri, prognostik faktörleri ve sağkalımları incelenmektedir.

Malign melanom beşinci dekatda pik yapan bir hastalık olup 15-70 yaş arasında görülebilmektedir. Van der Sperk Kreiger ve arkadaşlarının 8500 serilik çalışmasında ortalama yaş 46 bulunmuştur(4). Uehera ve arkadaşlarının 103 hastalık çalışmasında ortalama yaş 55 iken Kandolf-Sekulović ve arkadaşlarının 266 hastalık çalışmasında 57 olarak saptanmıştır(5,6). Bir başka çalışma $\mathrm{Wu}$ ve arkadaşları tarafindan Amerika Birleşik Devletleri'nde yapılmış ve siyah ırkta melanoma yakalanma ortalama yaşı 63 iken beyaz 1rkta 59 olarak bildirilmiştir(7). Baş boyun bölgesine lokalize malign melanom hastalarının değerlendirildiği bir çalışmada ortalama tanı yaşı 67 olarak saptanmıştır(8). Bizim çalışmamızda ortalama yaş 52 olup literatür değerlerine yakın bulunmuştur.

Malign melanom her iki cinsiyette görülebilen bir tümör olup çok az fark da olsa kadınlarda daha sık görülmektedir. Amerikan
Ulusal Kanser Enstitüsü'nün verilerine göre kadın/erkek oranı $1.02 / 1 \quad$ olarak saptanmıştır(9). $\mathrm{Wu}$ ve arkadaşlarının çalışmasında siyah 1rkta, İspanyol kökenli Latin Amerikalılarda, İspanyol kökenli olmayan Amerikan Hindularında malign melanom kadınlarda daha sık görülürken beyaz 1rkta erkeklerde sik saptanmıştır(8). Chi ve arkadaşlarının 522 vakalık çalışmasında erkek ve kadın yüzdesi sırasıyla $\% 52$ ve $\% 48$ olarak saptanmıştır(10). Marashi-Pour ve arkadaşlarının çalışmasında da erkeklerde daha sık saptanmıştır(11). Sneyd ve arkadaşlarının Yeni Zelanda'da yaptıkları çalışmada Avrupa kökenli ve maori yerlilerinde kadınlarda daha s1kken pasifik kökenlilerde erkeklerde daha sik saptanmıştır(12). Sadece baş boyun bölgesine lokalize malign melanomların değerlendirildiği Berzina ve arkadaşlarının çalışmasında kadınlarda daha sik olarak saptanmıştır(9). Türkiye'de Doğan ve arkadaşlarının çalışmasında ise erkeklerde daha fazla oranda saptanmıştır(13). Bu retrospektif çalışmamızda çok az fark da olsa erkeklerde fazla saptanmıştır ve bu da daha çok beyaz ırkla yapılmış çalışmalara ve Doğan ve arkadaşlarının çalışmasına benzer olarak yorumlanabilir.

Malign melanom vücudun her tarafında görülebilmektedir. Bütün çalışmalarda prognozu değerlendirmek için ekstremiteler, baş-boyun ve gövde olarak üç kısma ayrılarak incelenmiştir. Ramnath ve arkadaşlarının çalışmasında 461 olgunun \%43,8'inde gövde, $\% 39,3$ 'ünde ekstremitelerde, \%16,9'u baș boyun bölgesinde olarak rapor edilmiştir (14). Bir başka seride 612 olgunun \%47,8'i ekstremitelerde, \%44,1'i gövde, \% 8,1'i baş boyun bölgesinde lokalize olarak saptanmıştır (15). Marashi-Pour ve arkadaşlarının 52330 hasta içeren çalışmasında hastaların \%18'i baş boyun bölgesine lokalize, \%34'ü gövde ve $\% 48$ 'i ekstremite bölgesine lokalize olarak rapor edilmiştir(11). Sneyd ve arkadaşlarının çalışmasında baş boyuna lokalize olanlar $\% 19,1$, gövdeye lokalize olanlar \%31,1, ekstremiteye lokalize olanlar \%49,8 olarak saptanmıştır(12). $\mathrm{Bu}$ çalışmada gövde lokalizasyonlarındaki literatüre göre düşük, ekstremite lokalizasyondakilerin oranı benzer, baş boyun bölgesine lokalize olanların biraz daha fazla bulunmuştur ve bunu da bu bölgedeki malign melanomlu olguların yüksek 
riski nedeniyle diğer kliniklerden hasta refere edilmesinin fazla olmasına bağlanabilir.

Malign melanomda daha önceden yapılan çalışmalarda breslow kalınlığı ile primer tümör bölgesinin yerleşimi arasındaki ilişki araştırılmış ve baş boyun bölgesi yerleşimli olanlarda breslow kalınlığının daha fazla olduğu saptanmıştır. Sneyd ve arkadaşlarının çalışmasında baş boyun bölgesi yerleşimli olanlar diğer bölgelere göre daha büyük breslow kalınlığ 1 ortalamasına sahip saptanmıştır(12). $\mathrm{Bu}$ çalışmada breslow kalınlığı ortalamasına bakılmamış fakat breslow kalınlığı $4 \mathrm{~mm}$ ve üstünde olanların büyük çoğunluğu baş boyun bölgesine lokalize olanlarda saptanmış ve Sneyd ve arkadaşlarınının çalışmasına paralel sonuç vermiştir.

Malign melanomda sağkalımı etkileyen en önemli faktörlerden biri cinsiyet olarak bilinmektedir ve özellikle erkek cinsiyetinde sağkalımın daha kısa olduğu önceki çalışmalarda saptanmıştır. Levi ve arkadaşlarının yaptıkları çalışmada cinsiyetin sağkalımı etkileyen iki önemli faktörden biri olduğunu saptamışlar ve erkek cinsiyetin daha kısa yaşam süresine sahip olduğunu saptamışlardır(16). Aynı şekilde Balch ve arkadaşlarının 17600 malign melanom hastasını inceledikleri çalışmada da erkek hastalar kadın hastalara kıyasla daha az yaşamakta olduklanı rapor edilmiştir(17). Marashi-Pour ve arkadaşlarının çalışmasında erkek cinsiyette olanlar kadın cinsiyete göre daha kısa yaşam süresine sahip oldukları saptanmıştır(11). $\mathrm{Bu}$ çalışmada literatürle uyumlu saptanmış ve erkekler istatistiksel olarak anlamlı olacak şekilde daha kısa yaşam süresine sahiptir. $\mathrm{Bu}$ da erkeklerde kozmetik kaygıların daha az olması nedeniyle doktora daha geç başvurmaları ve daha kalın tümörleri veya ülserasyonlu tümörlerinin daha fazla olabileceğine bağlanabilmektedir.

Melanomun primer yerleşim yerine göre yapılan sağkalım analizlerinde baş boyun yerleşimli olanlar diğerlerine göre daha kısa sağkalım ile bağlantılı bulunmuştur. Levi ve arkadaşlarının çalışmasında en uzun extremite, ikinci gövde ve üçüncü başboyun bölgesi olarak saptanmıştır(16). Fortes ve arkadaşlarının çalışmasında en düşük sağkalım baş boyun bölgesine lokalize olanlarda saptanmış sonra sırasıyla gövde ve extremiteler olarak sıralanmıştır(18). Crocetti ve arkadaşlarının çalışmasında baş boyun bölgesi ve diğerlerini bir grup olarak değerlendirmişler ve baş boyun bölgesine lokalize olanlarda sağkalımın daha kı olduğunu saptamışlardır(19). Callender ve arkadaşlarının çalışmasında en kısa sağkalım baş boyun bölgesine lokalize olanlarda saptanırken en uzun sağkalım extremite bölgesinde saptanmıştır(20). Bu çalışmada da literatüre benzer olarak baş boyun bölgesine lokalize olanlar daha kısa sağkalım ile bağlantılı saptanmış fakat istatistiksel anlamlılığa ulaşmamıştır.

Malign melanom metastaz potansiyeli yüksek bir tümördür. Bugüne kadar yapılan çalışmalarda en sık akciğere metastaz yaptığ bilinmektedir. Taş'ın yaptığı çalışmada en sık akciğer metastazı, sonra sirasiyla karaciğer, beyin ve kemik saptanmıştır(21). Bu çalışmada da literatür ile uyumlu olarak en sik akciğer metastazı saptanmıştır.

Malign melanomda en iyi tanımlanmış prognostik faktörlerden birisi breslow kalınlığ 1 olup breslow kalınlığ 1 arttıkça sağkalım kısalmaktadır. Ramnath ve arkadaşları 480 hastalık çalışmasında breslow kalınlığı ile sağkalım arasında ters ilişki saptamışlardır(14). Levi ve arkadaşları 1229 hasta içeren çalışmasında breslow kalınlığı arttıkça sağkalımın kısaldığını saptamışlardır(16). 612 hasta sayılı bir başka seride breslow kalınlığ 4 $\mathrm{mm}$ üstü ve altı olarak ayrılmış ve $4 \mathrm{~mm}$ üstü olanlar daha düşük sağkalım saptamışlar ve istatistiksel anlamlılığa ulaşmıştır(15). Marashi-Pour ve arkadaşlarının çalışmasında hem univariate hem multivariate analizde en önemli risk faktörü breslow kalınlığ 1 saptanmış ve breslow kalınlığı arttıkça yaşam süresi kısalmaktadır(11). Bu çalışmada 0-2 mm olanları bir grup 2-4 mm olanları bir grup ve 4 $\mathrm{mm}$ ve üstünde olanları bir grup olarak değerlendirdik ve $4 \mathrm{~mm}$ üstünde olanlarda sağkalımın belirgin kısaldığını saptadık ve bu da daha önceki literatür verileri ile uyumlu bulunmuştur.

Malign melanom prognozu kötü bir deri tümörüdür. Türkiye' de sıklığı, prognozuna etki eden faktörler ile ilgili çalışma sayısı oldukça azdır. Ülkemizde çok merkezli prognozu etkileyen faktörleri inceleyecek çalışmalara ihtiyaç vardır. $\mathrm{Bu}$ çalışmada literatürde yayınlanan yayınların sonuçlarına benzer sonuçlar çıkmış fakat hasta sayısının yetersizliği nedeniyle istatistiksel anlamlılığa 
ulaşmamışıtır. Çalışmamızın hasta sayısı az da olsa mevcut verilerimiz, Ege ve Akdeniz bölgesinin malign melanom özelliklerini yansıtması açısından bilgi verebilecek bir özellik taşımaktadır.

\section{Çıkar Çatışması:Yok.}

\section{Referanslar}

1. Bamhill RL, Fandrey K, Levy MA, Mihm ML, et al. Angiogenesis and tumor progression of melanoma. Quantification of vascularity in melonocytic nevi and cutaneus malign melanoma 67:331,1992

2. Bamhill RL, Mihm M. Histopatology and precursör lesions. In Balch CM, Houghton AN, Sober AJ Soong SJ: cutaneus melanoma ed 3.sd Louis Quality Medical Publishing 1998 s. 103-108

3. Haluza D, Simic S, Moshammer H. Temporal and spatial melanoma trends in Austria: an ecological study. Int J Environ Res Public Health. 2014 Jan 6;11(1):73448.

4. Van Der Sperk-Kreijser LM, Van Der Rhee SJ, T'oth G, Van Westering R, et al. Site, histological type, and thickness of primary cutaneous malignant melanoma in western Netherlands since 1980. Br J Dermatol 1997; 136(4): 565-71.

5. Uehara S, Kamo R, Harada T, Ishii M. Survival analysis of malignant melanoma in Japan--multivariate analysis of prognostic factors. Osaka City Med J. 2009 Jun;55(1):35-52.

6. Kandolf-Sekulović L, Zivković-Perišić S, Radević T, Rajović M, et al. Melanoma in South-East Europe: epidemiological data from the central cancer registry and clinicopathological characteristics from the hospitalbased registry in Serbia. Int J Dermatol. 2012; 51(10): 1186-94.

7. Wu XC, Eide MJ, King J, Saraiya M, et al. Racial and ethnic variations in incidence and survival of cutaneous melanoma in the United States, 1999-2006. J Am Acad Dermatol 2011; 65(5 Suppl 1): 26-37.

8. Berzina A, Azarjana K, Cema I, Pjanova D, et al. Prognostic factors and epidemiological characteristics of cutaneous and mucosal head and neck melanoma. Stomatologija 2011; 13(2): 49-54.

9.Horn JW, Asire AJ, Young JL. SEER Program: Cancer Incidence and mortality in the United States 19731981(NIH Publication No. 85-1837) Bedhesta, National Cancer Institute, 1984.

10. Chi Z, Li S, Sheng X, Si L, et al. Clinical presentation, histology, and prognoses of malignant melanoma in ethnic Chinese: A Study of 522 consecutive cases. BMC Cancer 2011; 11: 85-95.

11. Marashi-Pour S, Morrell S, Cooke-Yarborough C, Arcorace $\mathrm{M}$, et al. Competing risk analysis of mortality from invasive cutaneous melanoma in New South Wales: a population-based study, 1988-2007. Aust N Z J Public Health 2012; 36(5): 441-5.

12. Sneyd MJ, Cox B. Clinical and histologic factors associated with melanoma thickness in New Zealand Europeans, Maori, and Pacific peoples. Cancer 2011; 117: 2489-98.

13. Dogan M, Arslan ÜY, Tokluoglu S, Özal G, Selvi H, Utkan G, Akbulut H, Yalçın B, İçli F. Malign
Melanomalı Doksan Hastanın Klinikopatolojik Değerlendirmesi. Açta Oncologica Turcica 2009;42:5760

14. Ramnath EM, Kannath D, Brabeil A, Stall A, et al. Lymphatic mapping for melanoma: Long term results of regional nodal sampling with radioguided surgery. Cancer Control 1997; 4(6): 483-90.

15. Gershenwald JE, Thomps W, Mansfield PF, Leed JE, et al. Multi instituinal Melanoma Lymphatic mapping experience: The prognostic value of Sentinel lenf nod status in 612 stage I or II melanoma patients. J Clin Oncol 1999; 17(3): 976-83.

16. Levi F, Randimbison L, La Vecchia C, Te WC, et al. Prognostic Factors for Cutaneous Malignant Melanoma in Waud, Switzerland. Int J Cancer 1998; 78(3): 315-9.

17. Balch CM, Soong SJ, Gershenwald JE, Thompson JF, et al. Prognostic factors analysis of 17,600 melanoma patients: validation of the AJCC melanoma staging system. J Clin Oncol 2001; 19: 3634.

18. Fortes C, Mastroeni S, Sera F, Concolino F, et al. Survival and prognostic variables of cutaneous melanoma observed between 1995 and 2000 at Istituto Dermopatico Dell'Immacolata (IDI-IRCCS), Rome, Italy. Eur J Cancer Prev 2006; 15(2): 171-7.

19. Crocetti E, Mangone L, Lo Scocco G, Carli P. Prognostic variables and prognostic groups for malignant melanoma. The information from Cox and Classification And Regression Trees analysis: an Italian populationbased study. Melanoma Res 2006; 16(5): 429-33.

20. Callender GG, Egger ME, Burton AL, Scoggins CR, et al. Prognostic implications of anatomic location of primary cutaneous melanoma of $1 \mathrm{~mm}$ or thicker. Am J Surg 2011; 202(6): 659-64.

21. Taş F. Metastatic behavior in melanoma: Timing, Pattern, Survival, and İnfluencing Factors. J Oncol 2012; 2012: 647684 . 